\title{
The Profile of Child and Teenager Students' Physical Activity
}

\author{
Nuraeni Septiawati ${ }^{*}$, Amung Ma'mun, Bambang Abduljabar \\ Department Sport of Education \\ Universitas Pendidikan Indonesia \\ Bandung, Indonesia \\ *nuraeniseptiawati@gmail.com
}

\begin{abstract}
The research is motivated by the problem of physical inactivity which is a problem in the world of education, especially for students. The purpose of this study was to determine the profile of physical activity of adolescents and children's students in elementary, junior high and high school. The method used in this study is a survey research with a quantitative approach. The design of this study is the Cross Sectional Survey, the population in this study were elementary school students, junior high schools and high schools in the city of Sukabumi with an age range of 8-19 years. Sampling is done by Cluster Random Sampling with a total sample of students is $\mathbf{1 0 0 8}$ students. The instrument used was Physical Activity Questionnaire for Adolescent (PAQ-A) and Physical Activity Questionnaire for Children (PAQ-C) and documentation. The conclusion is that physical activity in students of children is higher than that of female students and adolescents have lower physical activity values than male students both adolescents and children. The implication of this research is that it can improve the physical activity of adolescent and children in Sukabumi City, general in Indonesia and make various parties aware of the importance of the role of physical activity.
\end{abstract}

Keywords—physical activity; adolescents; children's and students

\section{INTRODUCTION}

The problem of student physical activity in the world of education is one of the factors that deserve attention. Physical activity is not significantly related to health behavior, while the role of education for students shows the strongest association for students [1]. In reality, students in schools are only given the opportunity of one meeting a week with a time range of 70 120 minutes to take physical education and health lessons, this is not enough in obtaining student health. Physical activity can have a positive impact on health inequalities among African Americans. Students in African American students feel positive about physical activity but most do not meet the recommended level [2]. Therefore, it is very important for the school to provide space for students to do any positive activities in the school environment.

In the study, Bredley proved that the way to get the results of physical activity that is recommended is to do physical activities that are routine in their daily lives [3]. As for the study rural South African male and female adolescents showed time spent in sedentary behavior [4]. Simple interventions such as street lighting, sidewalks, trees on the streets, seats, bicycle paths or walkways, bicycle racks, and devices that facilitate traffic seem promising in promoting physical activity in the environment [5]. This existence must be in harmony with government policy, as in its study present two case studies in relation to physical activity policies from Scotland and Ireland, that lack of relevant policies on physical activity policies resulting in obstruction benefits of education and physical education policies [6]. Many elements are involved in maximizing physical activity in adolescents and children, so complex is the need for data in the field to prevent the creation of inactive or sedentary life regeneration.

When talking about government policies, the central government, local government and school policies will affect students in school. Considering that the research will be conducted in the city of Sukabumi, the researchers highlight Sukabumi city regulations regarding the implementation of sports, chapter $\mathrm{v}$, the second part, Article 9, that the development and development of educational sports aims to: improve physical and psychological quality, improve physical and spiritual health, build character sportsmanship, sports skills, and developing sports interests and talents [7]. In this regulation it is clearly intended that educational sports can improve students' physical quality, but other points prioritize student achievement in exercise. This is less relevant because the education area should only be the domain of education, namely physical education and not for sports achievement because it is outside physical education. This is like being a concern for all of us so that the physical quality of students becomes a major concern in educational sports.

In his journal Kelley A. George \& Kelley S. Kristi about "Physical Activity Habits of African-American College Students" concluded that his research statistically shows the tendency for groups categorized as students who choose physical activity themselves to be more active in participating [8]. Researchers also mentioned that African-American students, especially girls, had lower levels of physical activity. In addition to being related to gender, we needed to know the profile of physical activity in children and adolescents as an effort for us to minimize the occurrence of sedentary life as we age to avoid sedentary life. 


\section{METHOD}

This study uses survey research methods with a quantitative research approach. In this study the design used is a crosssectional survey, which is a model in obtaining data in one way in a short period of time. Participants in this study were elementary school students, junior high school and high school both female and male in Sukabumi City. Characteristics of the study participants were participants in the age range of 8-19 years, obtained a sample of 348 elementary school students, 334 junior high school students, and 326 high school students so that the total sample of students obtained was 1008 students both male and female .

This study uses a questionnaire as measured by The Physical Activity Questionnaire Manual for Children (PAQ-C) and The Physical Activity Questionnaire Manual for Adolescent (PAQ-A) by Kent C. Kowalski, et al in 2004 which has been modified [9]. Data collection techniques using a validation and reliability questionnaire have been measured, [in the form of a questionnaire with several statements about activities carried out by students during the past week. Changes or adjustments in the questionnaire are caused by differences in conditions or physical / sports activities carried out between Canada and Indonesia. For the process of modification or adjustment is done in terms of language, namely from English translated into Indonesian, then back to English using the help of an accredited translation agency and then analyzed by experts so that in language, the instrument is in accordance with the meaning of the original language of the questionnaire.

\section{RESULTS}

From the results of research obtained in adolescent students namely 504 samples. Get results that female and male students have a percentage that is not much different in the medium category, while in the low category female students are more than male students, so male students have more values in the high category, but none teenage students who reach very high categories. Can be described in the following picture:

The results of filling in the quessioner for adolescent students

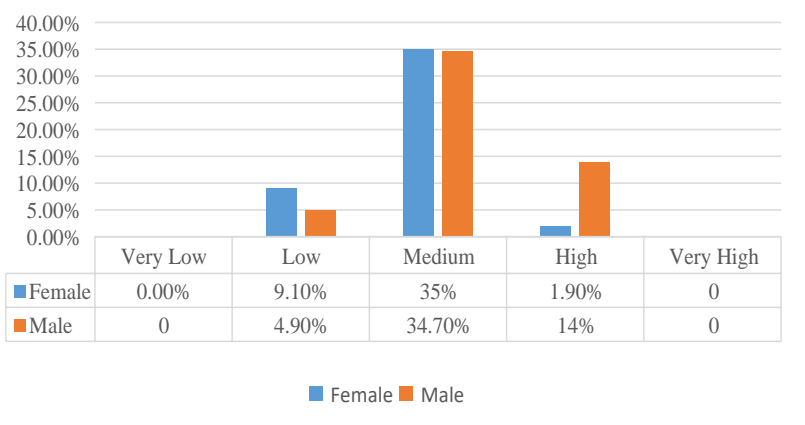

Fig. 1. The result of filling in the quessioner for adolescent students.

Whereas, from the results of research obtained in adolescent students namely 504 samples. Getting the results that female and male students have a percentage that is not much different in the medium category, while in the low category female students are more than male students, as well as male students have more values in the high category, but in child students These children have students who have very high grades in category. Can be described in the following picture:

The results of filling in the quessioner for the students of children

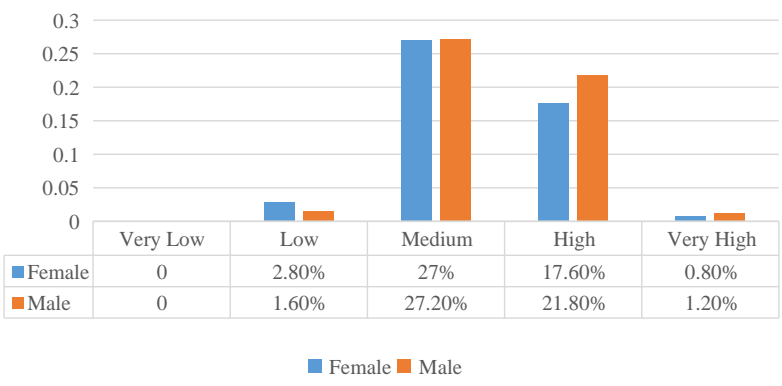

Fig. 2. The result of filling in the quessioner for children's students

From the results of research that male teenage boys have a higher percentage value compared to female adolescent students and female adolescent students have the highest physical activity values in the low category while male and female student physical activities are not much different from women even though boys are taller.

\section{DISCUSSION}

From the results of this study, it can be discussed that children's students have higher physical activity than female students and adolescents have lower grades than boys. This happens due to the many factors that influence it besides the characteristics of adolescent students and children differently, the environment and geographical location are influential. It is very important for the school to be able to facilitate their students to move so that they can maximize physical activity during school. Can be a reference for future researchers.

\section{CONCLUSION}

It can be concluded that male students have a higher physical activity than female and children's are more active than adolescent's students. The implication is that school students can pay attention to the physical activities of their students, especially on female adolescents.

\section{REFERENCES}

[1] M.T. Vuori, L.K. Kannas, J. Villberg, S.K. Ojala, J.A. Tynjälä and R.S. Välimaa, "Is physical activity associated with low-risk health behaviours among 15-year-old adolescents in Finland?" Scandinavian journal of public health, vol. 40 , no. 1, pp. 61-68, 2012..

[2] K.A. Karen and W.S. Ralph, "Physical Activity Behaviors of Students of a Rural Historically Black College" Journal of American College Health vol. 58, no. 4, pp. 327-334, 2010.

[3] B.L. Ebba,"Physical Patterns in Older Men," Physical \& Occupational Therapy In Geriatrics, 2015.

[4] L.K. Micklesfield, T.M. Pedro, K. Kahn, K., J. Kinsman, J.M. Pettifor, S. Tollman and S.A. Norris, "Physical activity and sedentary behavior 
among adolescents in rural South Africa: levels, patterns and correlates," BMC public health, vol. 14, no. 1, pp. 40, 2014.

[5] C. Lee and A.V. Moudon, "Neighbourhood design and physical activity," Building research \& information, vol. 36, no. 5, pp. 395-411, 2008.

[6] C.B. Woods and N. Mutrie, "Putting physical activity on the policy agenda," Quest, vol. 64, no. 2, pp. 92-104, 2012.
[7] RAPERDA Kota Sukabumi, Penyelenggaraan Keolahragaan. Sukabumi, 2015.

[8] G.A. Kelley and K.S. Kelley, "Physical activity habits of AfricanAmerican college students," Research quarterly for exercise and sport, vol. 65, no. 3, pp. 207-212, 1994.

[9] K.C. Kowalski, The Physical Activity Questionnaire for Older Children (PAQ-C) and Adolescents (PAQ-A) Manual. Canada, 2004. 